\title{
Immunomagnetic separation and rapid detection of bacteria using bioluminescence and microfluidics
}

\author{
Jingmin Qiu ${ }^{\mathrm{a}}$, Yun Zhou ${ }^{\mathrm{b}}$, Hui Chen ${ }^{\mathrm{b}}$, Jin-Ming Lin ${ }^{\mathrm{a}, \mathrm{b}, *}$ \\ a State key Laboratory of Environmental Chemistry and Ecotoxicology, Research Center for Eco-Environmental Sciences, Chinese Academy of Science, \\ P.O. Box 2871, Beijing 100085, China \\ ${ }^{\mathrm{b}}$ The Key Laboratory of Bioorganic Phosphorus Chemistry \& Chemical Biology, Department of Chemistry, Tsinghua University, Beijing 100084, China
}

\section{A R T I C L E I N F O}

\section{Article history:}

Received 17 March 2009

Received in revised form 30 April 2009

Accepted 4 May 2009

Available online 12 May 2009

\section{Keywords:}

Immunomagnetic bead

Bacteria

Salmonella

Staphylococcus aureus

Bioluminescence

Microfluidics

\begin{abstract}
A B S T R A C T
This paper describes an immunomagnetic separation of target bacterial cells from others by using magnetic bead. The surface of bead was coated with antibodies which can capture specific organism. The binding efficiency of immunomagnetic bead (IMB) capturing target bacterial cells was higher than $98 \%$ when the concentrations of target and interferent bacterial cells were at the same level. The concentration of bacteria was determined indirectly by detecting adenosine $5^{\prime}$-triphosphate (ATP) employing bioluminescence (BL) reaction of firefly luciferin-ATP. Benzalkonium chloride (BAC) was used as an ATP extractant from living bacterial cells. We found that BAC could enhance the light emission when the concentration of BAC was less than $5.3 \times 10^{-2} \%(\mathrm{w} / \mathrm{v})$ and the BL intensity reached its maximum at the concentration of BAC was $2.7 \times 10^{-2} \%$, which was 10 -fold stronger than that without BAC. Based on the principle of the IMB, a microfluidic chip combined with immunofluorescence assay for separating and detecting bacteria simultaneously was also developed. The IMBs were magnetically fixed in the beadbeds of chip channels with a 3-mm diameter of NdFeB permanent magnet. The target bacterial cells can be captured magnetically and observed by a fluorescent microscope.
\end{abstract}

(C) 2009 Elsevier B.V. All rights reserved.

\section{Introduction}

Rapid detection of bacteria is necessary for the safety of food products, the veracity of clinical diagnostics, the future progress of gene engineering, the prohibition of threat of possible biological warfare, etc. [1,2]. Previously, the microbiological methods, containing replication bacterial cells to $10^{9} \mathrm{cell} / \mathrm{mL}$, specific identification on selective media and biochemical tests, provided us a traditional way to detect bacteria, which usually cost several days [3]. So a truly rapid and sensitive monitoring system for detecting and identifying bacteria is in great demand. Adenosine $5^{\prime}$-triphosphate (ATP) is present in all living cells and the amount of it per cell remains fairly constant $\left(\sim 10^{-18} \mathrm{~mol} / \mathrm{cell}\right)$ [4]. Therefore, an assay of ATP is responsible for the concentration of bacterial cells. Firefly bioluminescence $(\mathrm{BL})$ is routinely used for the detection of ATP due to the number of photons (BL intensity) is directly proportional to the concentration of ATP [5-7], which can be measured at femtomole levels using the luciferin-ATP reaction [8].

\footnotetext{
* Corresponding author at: Department of Chemistry, Tsinghua University, Qinghua Yuan, Haidian, Beijing 100084, China. Tel.: +86 10 62792343; fax: +86 10 62792343.

E-mail address: jmlin@mail.tsinghua.edu.cn (J.-M. Lin).
}

In the assay of intracellular ATP from bacterial cells, ATP extractants are used for releasing ATP from living bacterial cells. Plenty of choices in ATP extractant are available, such as trichloroacetic acid (TCA), Triton X-100, ethanol, and benzalkonium chloride (BAC). Among ATP extractant, BAC is widely used because it can extract ATP from more living cells especially bacteria [9]. Previously, it is reported that BAC inhibits the activity of luciferase besides releasing ATP in the BL reaction; the way to eliminate the inhibitory effect is to dilute the extracts containing intracellular ATP and BAC, thus resulting in lowing of sensitivity for determining ATP. Another method to eliminate the inhibitory effect, which does not induce a decrease in determining ATP, is to use liposome, composed of phosphatidylcholine and cholesterol, the function of which in $\mathrm{BL}$ reaction is achieved by associating with BAC before BAC inhibiting luciferase [10-12]. However, there are some disadvantages by introducing liposome: the procedure is too complex; it costs too much time in synthesizing satisfied liposome for the BL reaction; the improved degree in sensitivity by the liposome is limited. So it is necessary to establish a more convenient method to improve the sensitivity in the BL reaction. According to experiments, we found that when the concentration of BAC was less than some value, BAC itself could enhance the BL intensity, which means that it does not need other reagents to improve the sensitivity in the BL reaction.

The immunomagnetic bead composed of magnetic particle core inside and polymer group conjugated by antibodies on the sur- 
(A)

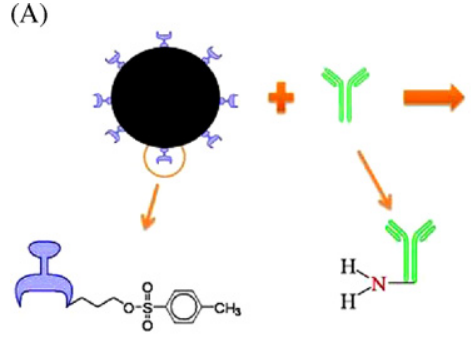

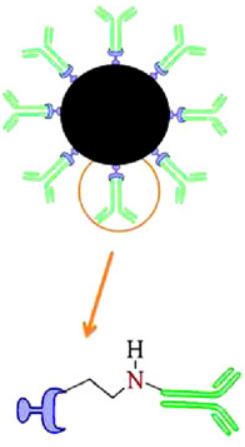

(B)

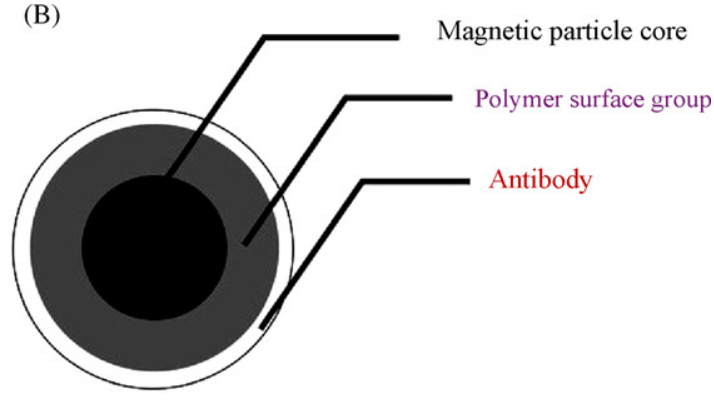

(C)

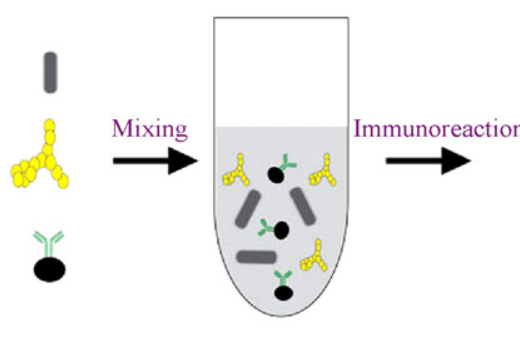

Target bacteria

Interferent bacteria

Immunomagnetic bead

Removing supernatant

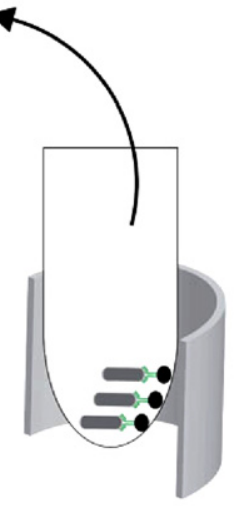

Magnet

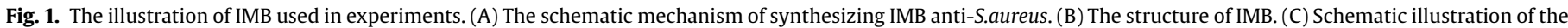
immunomagnetic separation process for separating Salmonella in a tube of the bioluminescence method. Scale bar $=10 \mu \mathrm{m}$.

face, are designed for immunomagnetic separation (IMS) [13]. Typically, the beads are $1-5 \mu \mathrm{m}$ spheres containing $\gamma-\mathrm{Fe}_{2} \mathrm{O}_{4}$, $\mathrm{MeFe}_{2} \mathrm{O}_{4}(\mathrm{Me}=\mathrm{Co}, \mathrm{Mn}, \mathrm{Ni})$, and $\mathrm{Fe}_{3} \mathrm{O}_{4}$ to make them superparamagnetic in the presence of magnetic field. The antibody coated on the surface of the IMB could capture the target organism when they are close to IMB. So IMS is a rapid, specific, efficient and technically simple method that can be used for separation of target organism directly from non-target organism and other particles without any need for centrifugation or filtration [14-16].

Microfluidic systems, an attractive platform for rapid few cells functional analysis, appear to offer a powerful means to automate and miniaturize sample preparation for bioassays [17-19]. On-chip assays using micron-sized fluidic channels have demonstrated the ability to perform rapid and sensitive biological assays. In addition, the small dimensions of microdevices allow for the creation of portable analytic devices. Magnetic bead-beds within a microfluidic device was proposed for capturing cells in order to obtain a more controllable and compact magnetic bed, which can improve the capture efficiency. Furdui [20] reported a similar approach, in which the detection results were obtained by the PCR step. However, the PCR step is time consuming and off-line. So we developed an on-chip immunofluorescence assay for bacteria analyzing using microfluidic chip combined with the bacterial cells capture of IMB. Before introducing into microchip, bacterial cells were firstly mixed with the FITC-labeled antibodies, which supported an easily way to detect by charge coupled devices (CCD) in the microscope. Separation is achieved by bacteria-FITC-labeled antibodies complex captured by bead-beds in the chamber of microchannel [21], and detection is obtained by observing the fluorescent phenomena from the bead-beds.

In this paper, the optimum conditions on separating and detecting bacterial cells based on bioluminescence and microfluidics were studied. Salmonella (CGMCC 1.1552) and Staphylococcus aureus (S. aureus, CGMCC 1.363) were used as the test target bacteria, which were chosen to form a model system due to the ready availability of immunoassay reagents and they are the typical ones of gram positive and negative bacteria. Results from this analyte can be generalized and extended to other bacterial species by changing IMB and antibodies.

\section{Experimental}

\subsection{Chemical and reagents}

Salmonella (CGMCC 1.1552) and Staphylococcus aureus (S. aureus, CGMCC 1.363) are from China General Microbiological Culture Collection Center (Beijing, China). The magnetic beads were purchased from Invitrogen Dyanl (Oslo, Norway) and its diameter is $2.8 \mu \mathrm{m}$ in average. Luciferase from firefly (Photinuspyralis) and D-luciferin were obtained from Promega (Madison, USA). Benzalkonium chloride (BAC, Predominantly $\mathrm{C}_{12} \mathrm{H}_{25} \mathrm{~N}\left(\mathrm{CH}_{3}\right)_{2} \mathrm{C}_{7} \mathrm{H}_{7} \mathrm{Cl}$, also contains $\mathrm{C}_{12}$ and $\mathrm{C}_{16}$ homologues) was purchased from Sigma-Aldrich $\mathrm{Co}$. (USA). Adenosine 5 '-triphosphate disodium salt (ATP) and magnesium chloride were obtained from Amresco (Ohio, USA). EDTA, dithiothreitol, bovine serum albumin (BSA), D-glucose, and 2-[4(2-hydroxyethyl)-1-piperazinyl] ethanesulfonic acid (Hepes) were obtained from Genview (Texas, USA). Yeast extract and tryp- 
(A)

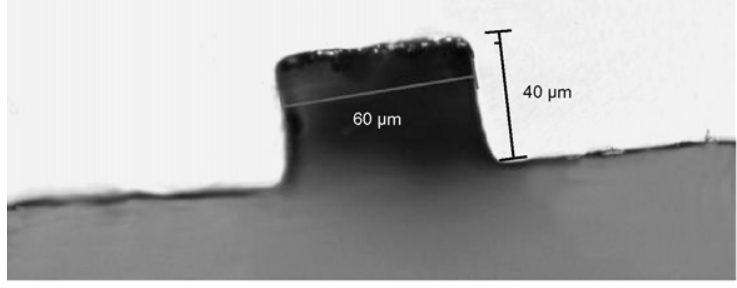

(C)

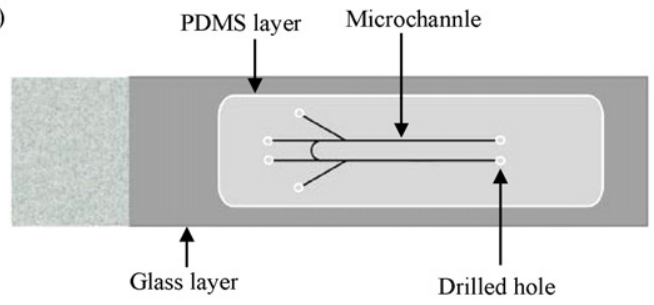

(D)

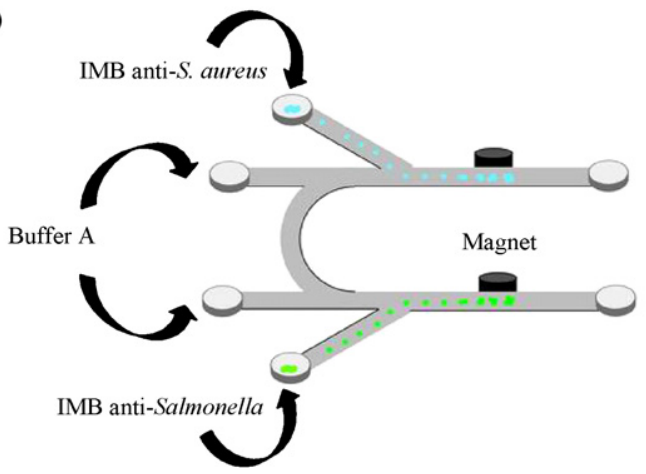

(B)
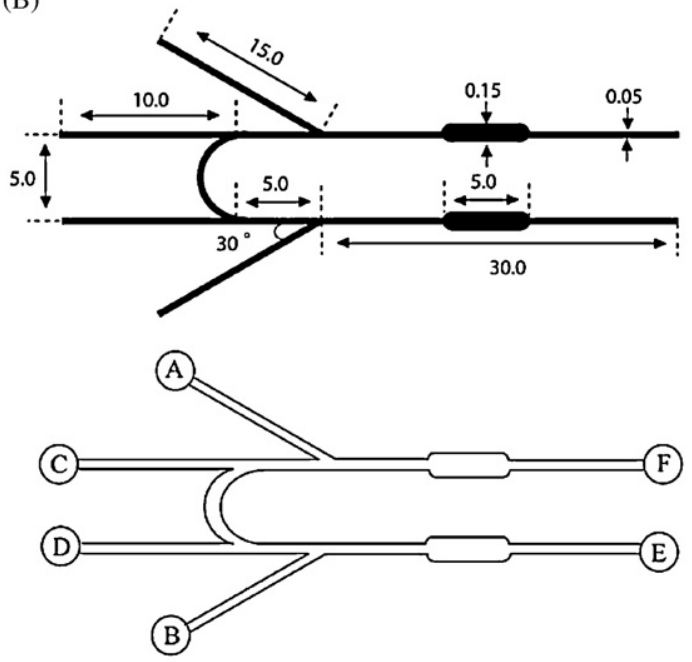

(E)

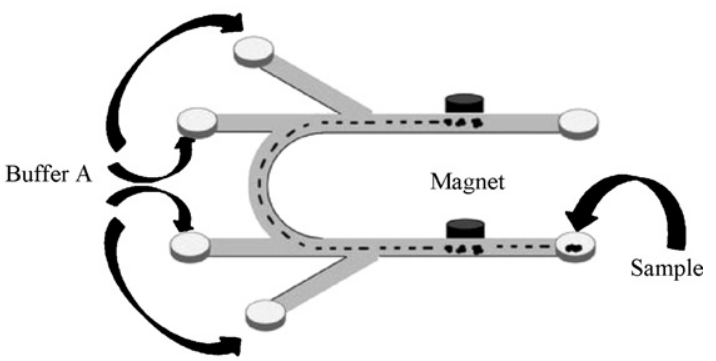

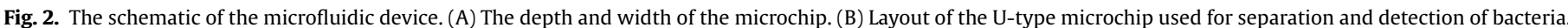

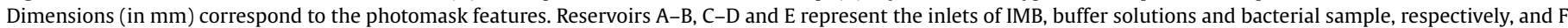

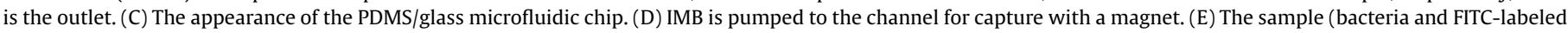
antibodies) is introduced from reservoir E. Beads show as blue and green streaks, sample as dark staff.

tone were purchased from Oxoid Ltd. (Basingstoke, Hampshire, England). Sodium chloride was obtained from Beihua Fine Chemicals Co., Ltd. (Beijing, China). Beef extract was purchased from Shuangxuan Microorganism Culture Factory (Beijing, China). IMB anti-Salmonella was obtained from Invitrogen Dynal (Oslo, Norway). FITC-labeled anti-Salmonella antibody, FITC-labeled anti-S. aureus antibody and anti-S. aureus antibody were purchased from Abcam (Cambridge, UK).

A $10.0 \mathrm{mM}$ solution of ATP was daily prepared by dissolving the compound with the "buffer A" (25 mM Hepes and 2.0 mM EDTA, $\mathrm{pH}$ 7.6). Working solution was prepared by serial dilution with the "buffer A". A $1.0 \%(\mathrm{w} / \mathrm{v})$ solution of BAC was prepared by dissolving the compound with the "buffer A", and stored at $4{ }^{\circ} \mathrm{C}$. A luciferase solution was prepared by dissolving $50 \mathrm{mg}$ of luciferase in $10 \mathrm{~mL}$ of "buffer L" (25 mM Hepes, $2.0 \mathrm{mM}$ EDTA, $20 \mathrm{mM}$ magnesium chloride, $1.2 \mathrm{mg} / \mathrm{mL} \mathrm{BSA}$, and $2.0 \mathrm{mM}$ dithiothreitol, $\mathrm{pH} 7.6$ ); a luciferin solution was prepared by dissolving $5 \mathrm{mg}$ luciferin in $5 \mathrm{~mL}$ with the "buffer L". The luciferase and luciferin solution were stored in portions of $200 \mu \mathrm{L}$ and $100 \mu \mathrm{L}$ at $-20^{\circ} \mathrm{C}$, respectively. When used, the two portions were mixed and $4.8 \mathrm{~mL}$ "buffer L" was added into the mixture. Other reagents were commercially available as analytical reagent or laboratory grade materials. All solutions were prepared with ultrapure deionized water from a UV ultrapure water system (EASYpure ${ }^{\circledR}$ II, Barnstead International, USA).

The multilite luminometer containing the equipment of chemiluminescence and UV detection was obtained from Biotech
(Synergy 4, Vorment, USA). The microscope (DMI 4000) and the fluorescent source (CTR 4000) were purchased from Leica (Wetzlar, Germany).

\subsection{Preparation of bacteria samples}

The target organism was Salmonella; the interferent bacterial cell was S. aureus. They were grown $3-5 \mathrm{~h}$ at $37^{\circ} \mathrm{C}$ in BPY culture $(10 \mathrm{~g} / \mathrm{L}$ tryptone, $5 \mathrm{~g} / \mathrm{L}$ beef extract, $5 \mathrm{~g} / \mathrm{L}$ yeast extract, $5 \mathrm{~g} / \mathrm{L} \mathrm{D}$-glucose, and $5 \mathrm{~g} / \mathrm{L}$ sodium chloride). The culture was grown to midlog phase $\left(\mathrm{OD}_{600}=\sim 0.6\right)$. Optical density at $600 \mathrm{~nm}\left(\mathrm{OD}_{600}\right)$ was measured with the multilite luminometer in a 96-well plate. The bacterial cells were collected by centrifugation at $10,000 \mathrm{rpm}$ for $5 \mathrm{~min}$ at $4{ }^{\circ} \mathrm{C}$ by a centrifuge (centrifuge $5804 \mathrm{R}$, Eppendorf, USA). The pellet was suspended in $1.0 \mathrm{~mL}$ of the "buffer A" solution. Working cell suspensions were prepared by serially diluting with the "buffer A" solution. All bacteria suspensions were stored on a crushed ice bath until the extraction of ATP from bacterial cells.

For microfluidics, FITC-labeled anti-Salmonella antibody and FITC-labeled anti-S. aureus antibody were diluted with "buffer A" solution to reach the final dilutions of $1: 40$ and $1: 10$, respectively. The number of working bacterial cells in the process of serially diluting was 3, which meant the bacterial cells in the experiment had been diluted by 1000 -fold. Then, the antibody and cells were mixed and shaken up for 5 min on a crash ice bath according to the relationship of antibody-antigen. 


\subsection{Bioluminescence detection}

The BL experimental procedure consisted in pipetting a 100$\mu \mathrm{L}$ portion of the ATP (standard samples or intracellular extracts) solution into a well of 96-well plate in the multilite luminometer. Then a $50-\mu$ L of portion of luciferase-luciferin mixture solution was injected into the well. Light output was integrated for $10 \mathrm{~s}$, following a 2 s' delay (shaking), with readings presented as relative light units (RLU). Bacterial numbers in sample dilutions were determined as colony forming units (CFU) from triplicate plate counts.

For intracellular ATP assays, a $100-\mu \mathrm{L}$ portion of bacteria suspension was mixed with some portion of $1.0 \%$ BAC solution in a $2-\mathrm{mL}$ plastic cuvette to extract ATP from bacterial cells. After incubating on a crashed ice bath for approximately $5 \mathrm{~min}$, the extract was diluted with some portion of "buffer A" solution to make the final volume of mixture become $1.0 \mathrm{~mL}$. The $100-\mu$ Laliquot of the diluted extract was added into a well of 96 -well plate, and then $50-\mu \mathrm{L}$ portion of luciferase-luciferin mixture solution was injected into the well, light output was measured after $2 \mathrm{~s}$ ' shake in the multilite luminometer.

\subsection{Immunomagnetic separation}

IMB anti-S. aureus (Fig. 1A) was synthesized as the instructions of "Dynabeads ${ }^{\circledR} \mathrm{M}-280$ Tosylactivated"; the process was shown in Fig. 1A. Assays employing IMB anti-Salmonella (Fig. 1C) for separating Salmonella as showed in Fig. 1C were performed by taking $100-\mu \mathrm{L}$ portion of bacterial dilutions in a $2-\mathrm{mL}$ tube and adding 50 $\mu \mathrm{L}$ washed IMB anti-Salmonella dilution solution. These were mixed at room temperature using a Dynal MPC-1 sample mixer (Invitrogen Dynal AS, Oslo, Norway) for 10 min before being immobilized using a Dynal MPC magnet (Invitrogen Dynal AS, Oslo, Norway) for 2 min.
The immobilized beads were then washed with a $150-\mu \mathrm{L}$ portion of "buffer A" and re-suspended in $1 \mathrm{~mL}$ portion of "buffer A" after adding a $40-\mu \mathrm{L}$ portion of $1.0 \%$ BAC solution for bioluminescence assay.

\subsection{Chip fabrication}

Polydimethylsiloxane (PDMS)/glass microfluidic chip (Fig. 2C) was fabricated using the standard soft lithography method [22-25]. The microscale channels were designed using the Adobe Illustrator software and then printed out on a transparency by a high resolution puncher as shown in Fig. 2. The transparency was then used as the photomask in photolithography for the fabrication of a master on a silicon wafer. We used negative photoresist SU-8 2050 (MicroChem, Newton, MA, USA). PDMS (Silicone elastomer, Dow Corning, Midland Michigan, USA) prepolymer mixture consisting of monomer and curing agent with the mass ratio of 10:1 was poured on the SU-8/silicon wafer master and then cured at the temperature of $60^{\circ} \mathrm{C}$ for $0.5 \mathrm{~h}$. The peeled PDMS stamp (about $5 \mathrm{~mm}$ thick) with structures of the microchannels at the surface was then drilled six inlet and outlet holes. A glass slide (7105, Sail Brand, Jiangsu, China) was pre-cleaned in $\left(\mathrm{H}_{2} \mathrm{O}: \mathrm{NH}_{4} \mathrm{OH}(27 \%): \mathrm{H}_{2} \mathrm{O}_{2}(30 \%)=5: 1: 1\right.$, volumetric ratio) solution with stirring at around $70^{\circ} \mathrm{C}$ for $1 \mathrm{~h}$ and then rinsed with pure water and dried. The PDMS chip and the glass slide were oxidized using a Plasma Cleaner (PDC-32G, Harrick, USA) in atmosphere for $1.5 \mathrm{~min}$ and then immediately put into contact to form the PDMS/glass microchip. The depth and width (Fig. 2A) of microchip were $40 \mu \mathrm{m}$ and $60 \mu \mathrm{m}$, respectively.

For magnetic bead-beds, IMB for Salmonella and for $S$. aureus was introduced into microchannels from A and B inlet using a 250- $\mu \mathrm{L}$ syringe (gastight \#1725, Hamilton, Switzerland) by a pump (PHD 2000, Harvard, USA) for $10 \mathrm{~min}$ at $0.10 \mu \mathrm{L} / \mathrm{min}$, respectively, and
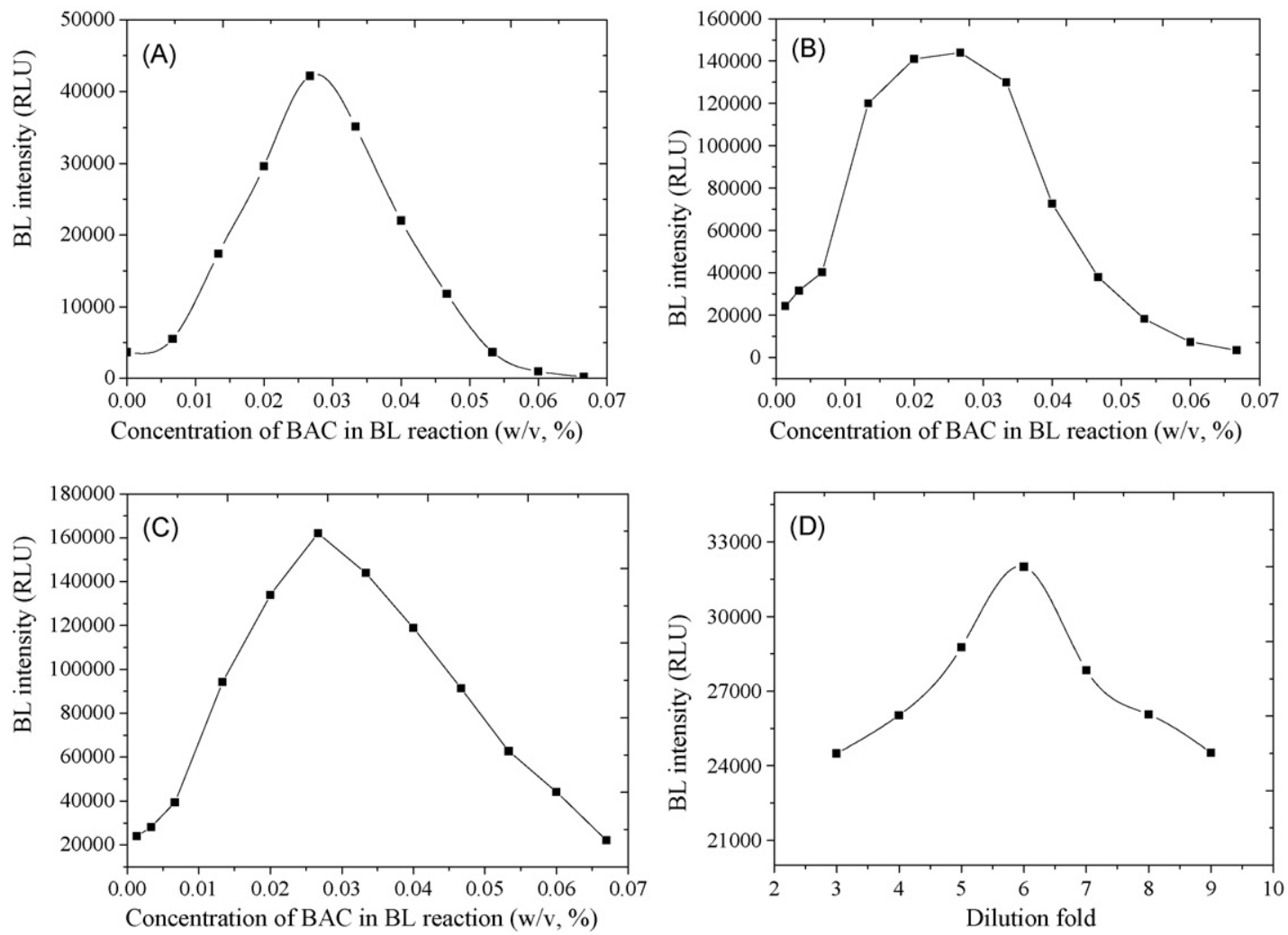

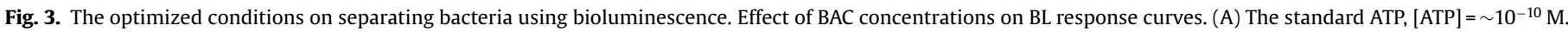

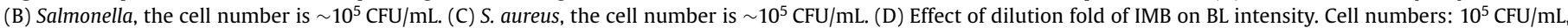
$[\mathrm{BAC}]=2.7 \times 10^{-2} \%$. 
captured magnetically with a $3 \mathrm{~mm}$ diameter $\mathrm{NdFeB}$ permanent magnet (Yingke Hongye Technical Corp., Beijing, China), as shown in Fig. 2D.

\subsection{Chip operating procedure}

Bead-beds were prepared as described, as shown in Fig. 2E, then the sample 1 (Salmonella, FITC-labeled anti-Salmonella antibodies) was firstly pumped through the chip from E inlet using a $100-\mu$ L syringe (gastight \#1710, Hamilton, Switzerland) for $20 \mathrm{~min}$ at $0.10 \mu \mathrm{L} / \mathrm{min}$, simultaneously other inlets except $\mathrm{F}$ were pumped "buffer A" at $0.05 \mu \mathrm{L} / \mathrm{min}$ in order to keep the sample flowing circularly in the U-type microchannel. Next, sample 2 (S. aureus, FITC-labeled anti-S. aureus antibodies) was introduced. The results were obtained by using the fluorescent microscope equipped with a digital camera under I3 filter set (470-490 nm).

\section{Results and discussion}

\subsection{Effect of $B A C$ on the $B L$ reaction}

To investigate the effect of $\mathrm{BAC}$ on the $\mathrm{BL}$ reaction, light emission was observed in standard ATP and intracellular ATP from Salmonella and $S$. aureus cells, respectively. The concentration of BAC was in the range of $6.7 \times 10^{-3}$ to $6.7 \times 10^{-2} \%$ in both mixtures. The results, as shown in Fig. 3, indicated the BL intensity and the amount of light emission were remarkably enhanced with the concentration of BAC increasing until $2.7 \times 10^{-2} \%$, after that the BL intensity decreased rapidly. Besides that, the BL intensity was stronger than that without BAC until the concentration of BAC was up to $5.3 \times 10^{-2} \%$. At the maximum point, the BL intensity was improved by a factor of 10 times compared to that without BAC. The mechanism of firefly bioluminescence decomposition can be deduced as follows [26].

Firefly luciferin reacts with ATP under the catalysis of luciferase and $\mathrm{Mg}^{2+}$, yielding adenylluciferin, a mid-product (reaction (1)), which will be oxidation by $\mathrm{O}_{2}$ according to nucleophilic acyl substitution, making $\mathrm{CO}_{2}$ is left and yielding oxyluciferin (reaction (2)), which is in the excited state (marked as *) and unstable. Next oxyluciferin* decays to the ground state, accompanied with light as the energy of emission from the reaction as the form of photons (reaction (3)):

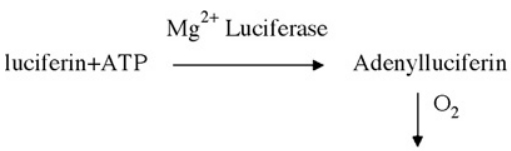

Oxyluciferin* (excited state) $+\mathrm{AMP}+\mathrm{CO}_{2}$

Oxyluciferin (groung state) + hv (light)

The reaction (1) is the rate-determining step (RDS) of the three reactions. So the above observations can be interpreted as follows. BAC, one of the cationic surfactants, the polar head of which can attract the anionic groups of luciferin and ATP, leads to accelerate the reaction (1) due to improve the combination of ATP and luciferin. Besides, BAC can inhibit the activity of luciferase. Therefore, before the concentration of BAC was up to $5.3 \times 10^{-2} \%$, the improvement from BAC could counteract its inhibitory effect, thus resulting the enhancement of BL intensity with increasing concentration of BAC. On the contrary, after the concentration of BAC was more than $5.3 \times 10^{-2} \%$, the inhibitory effect was dominant in the $\mathrm{BL}$ reaction, inducing the decrease of BL intensity.

The investigation in intracellular ATP from bacterial cells was shown in Fig. 3B (Salmonella) and Fig. 3C (S. aureus), which were examined by adding different volume of $1.0 \%$ BAC solution in a 100 -
Table 1

The BAC concentrations in releasing ATP and BL reaction.

\begin{tabular}{rll}
\hline Portion of adding BAC $(\mu \mathrm{L})$ & $\begin{array}{l}\text { Concentration of BAC } \\
\text { in releasing ATP }(\mathrm{w} / \mathrm{v})\end{array}$ & $\begin{array}{l}\text { Concentration of BAC } \\
\text { in BL reaction }(\mathrm{w} / \mathrm{v})\end{array}$ \\
\hline $100(1.0 \%)$ & $0.50 \%$ & $0.07 \%$ \\
$90(1.0 \%)$ & $0.47 \%$ & $0.06 \%$ \\
$80(1.0 \%)$ & $0.44 \%$ & $0.05 \%$ \\
$70(1.0 \%)$ & $0.41 \%$ & $0.05 \%$ \\
$60(1.0 \%)$ & $0.38 \%$ & $0.04 \%$ \\
$50(1.0 \%)$ & $0.33 \%$ & $0.03 \%$ \\
$40(1.0 \%)$ & $0.29 \%$ & $0.03 \%$ \\
$30(1.0 \%)$ & $0.23 \%$ & $0.02 \%$ \\
$20(1.0 \%)$ & $0.17 \%$ & $0.01 \%$ \\
$100(0.1 \%)$ & $0.05 \%$ & $0.01 \%$ \\
$50(0.1 \%)$ & $0.03 \%$ & $0.00 \%$ \\
$20(0.1 \%)$ & $0.02 \%$ & $0.00 \%$ \\
\hline
\end{tabular}

$\mu \mathrm{L}$ of bacteria dilution. The volume of $1.0 \%$ BAC was in the range of $10-100 \mu \mathrm{L}$, and the concentration of BAC in releasing ATP and $B L$ reaction was shown in Table 1 . Bacterial cell number of both is $\sim 10^{5} \mathrm{CFU} / \mathrm{mL}$. The trend of both curves in Fig. $3 \mathrm{~B}$ and $\mathrm{C}$ was as similar to Fig. 3A, which suggests: firstly, the reason for the enhancement and decrease of the BL intensity is from BAC instead of ATP; secondly, the activity of intracellular ATP and standard ATP was same in the BL reaction; finally, the efficiency of BAC releasing ATP is high. The BL intensity reached maximum when the concentration of $B A C$ was $2.7 \times 10^{-2} \%$ in both Fig. $3 \mathrm{~A}$ and $\mathrm{B}$, which means the optimum concentration of $\mathrm{BAC}$ is $2.7 \times 10^{-2} \%$ in this method of detecting bacteria.

\subsection{Measurement of ATP in bacterial extracts}

The calibration curve for standard ATP and intracellular ATP shown in Fig. 4 was prepared under the optimum concentration of BAC. The detection limit for ATP and bacteria was defined as the concentration of ATP and cell numbers that produced the BL intensity equal to 3 -fold of the blank intensity counted in the mixture containing no ATP or bacterial extracts. The detection limit of standard ATP in this method is $10^{-17} \mathrm{M}$ and the linear range is $10^{-17}-10^{-14} \mathrm{M}$. Correlation coefficient for linear regression analysis is indicative of small errors and excellent linear reliability $\left(r^{2}>0.996\right)$. In applications, as shown in Fig. $4 \mathrm{~B}$ and $\mathrm{C}$, the detection limit of both bacteria is $10 \mathrm{CFU} / \mathrm{mL}$ and the linear range is $10^{1}-10^{4} \mathrm{CFU} / \mathrm{mL}$, which is better than previous reports. So using this method we can detect bacterial cells even when they are in very low concentration.

\subsection{Immunomagnetic separation}

The efficiency of IMB capturing target bacterial cells is examined by condition of dilution fold and selectivity, and the results were shown in Fig. 3D and Table 2, respectively. The concentration of bacterial cells (Salmonella) is $\sim 10^{5} \mathrm{CFU} / \mathrm{mL}$, and incubation time is approximately $10 \mathrm{~min}$. Then the IMB capturing bacteria was removed by employing magnetic field. Next BAC was added in the washed bacteria-IMB complex suspension solution on a crashed ice bath to release ATP. Finally, luciferin-luciferase solution was injected in the extracts and detection began after shaking. The results, in Fig. 3D, show the BLintensity increased and reached maximum when dilution fold was 6 , after which BL intensity decreased with the dilution fold increasing. The reason for the increase in BL intensity is maybe due to the beads density decreases gradually with the dilution fold increasing, which results in the capacity of beads blocking releasing ATP is weaker than before. Later, that there are relatively fewer beads to capture bacteria with the dilution fold continuous increasing may well explain the decrease of BL inten- 

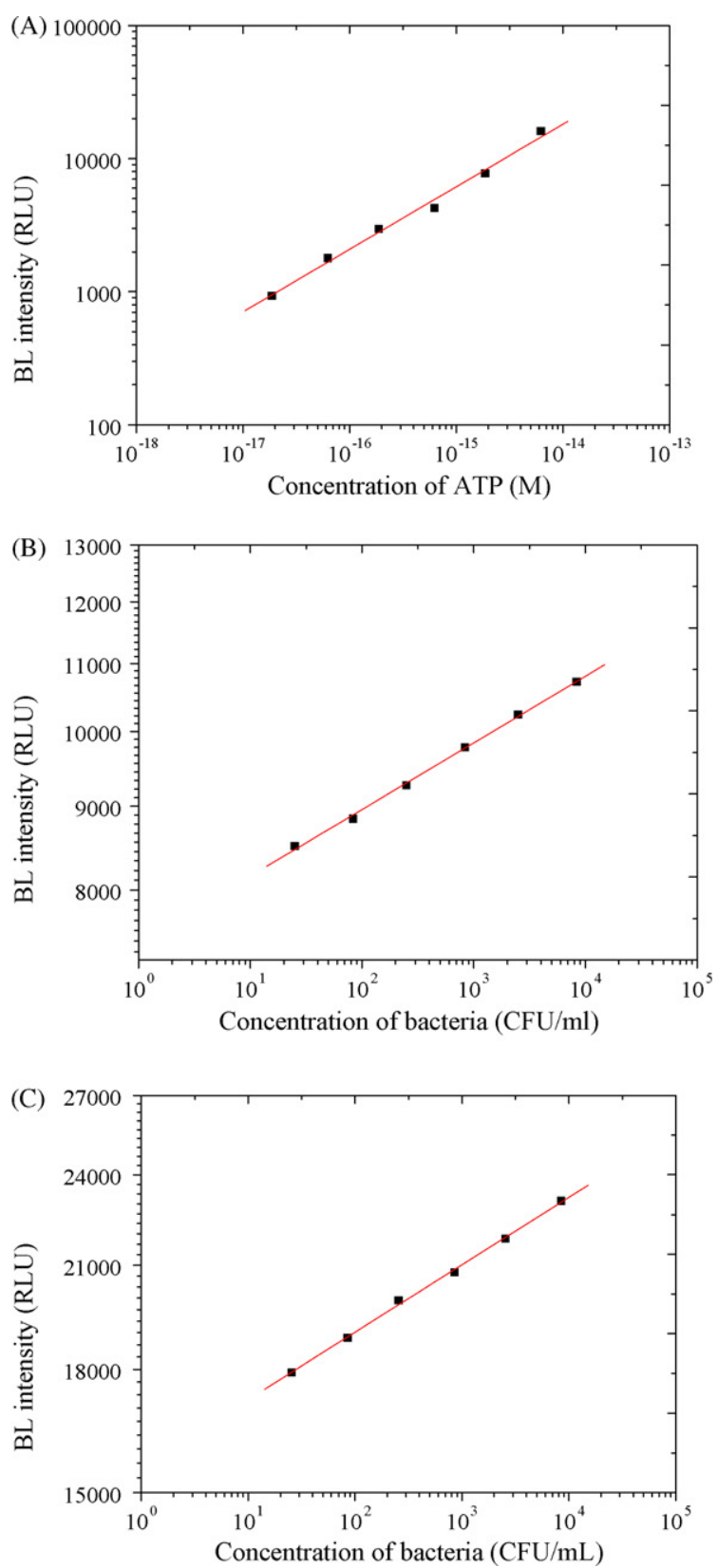

Fig. 4. The results of detecting bacteria using bioluminescence. Linear range of standard and intracellular ATP concentrations. $[\mathrm{BAC}]=2.7 \times 10^{-2} \%$. (A) Standard ATP's, $r^{2}=0.996$. (B) Salmonella's, $r^{2}=0.999$. (C) S. aureus', $r^{2}=0.999$.

sity. So the optimum dilution fold of IMB is 6 in immunomagnetic separation.

The selectivity of the IMB was examined by using the $S$. aureus as an interferent for the Salmonella target cells. The colonies produced by the two species onto BPY agar could be easily identified and separately counted (S. aureus, yellow; Salmonella, white). The results in Table 2 indicate no significant non-specific binding of S. aureus. However, the binding efficiency of the Salmonella was reduced in the presence of higher concentration of $S$. aureus. The experiments showed that, although not so much $S$. aureus cells were captured by the beads, there could have been non-specific binding of cell-free material, which appeared to interact with the antibodies on the beads with the effect of reducing the number of binding sites available to capture the Salmonella cells. Therefore, the selectivity of IMB in immunomagnetic separation is acceptable.

\subsection{Microfluidic chip method}

In order to make good use of IMB, magnetically captured beadbed was designed in a microfluidic chip (see Fig. 2). Initial formation of the bead-bed is an important step in preparing the device for sample capture. Bead capture was maximized through the use of an asymmetric magnetic field, achieved by placing a magnet on only one side of the chip. In the U-type microchip, the chamber (the part of the channel expanding outwards) provided a place to form beadbeds, shown in Fig. 5A and B, illustrating the magnetic beads were almost totally captured by the outside magnet and there was no bead in the microchannel.

Fig. 5C-H showed that there was no affinity between IMB and FITC-labeled antibodies and IMB alone could not be observed by the fluorescent microscope.

Fig. 6C and D demonstrated that when sample 1 (Salmonella and FITC-labeled anti-Salmonella antibodies) was introduced through the microchannel, only the bead-beds composed of the IMB antiSalmonella were observed, so did the bead-beds composed of IMB anti-S. aureus when sample 2 was introduced, shown in Fig. 6A and B. So it is suggested that the two kinds of bacterial cells were separated and detected simultaneously by using the U-type microchip.

\subsection{Primary application for detecting bacterial cells}

The optimized conditions for the separation and detection of target bacteria from interferent and others are described in Sections 2.2-2.4. To demonstrate the utility of this method, target bacterial cells (Salmonella) were measured with and without interferent bacterial cells ( $S$. aureus). One sample only contained target bacterial cells and the other also contained interferent bacterial cells. Initially, the number of bacterial cells in the two samples was very low, then the bacterial cells in the two samples replicated at the same condition until the culture was grown to midlog phase $\left(\mathrm{OD}_{600}=\sim 0.6\right)$ in $3-5 \mathrm{~h}$. The two samples were separated by using IMB and extracted ATP by BAC. Finally, whether or not the original sample contained the target bacterial cells could be judged by comparing the BL signals in the reaction of the extracts and luciferase-luciferin solution, because the signal from the sample in the presence of target bacterial cells must be stronger than that without target bacterial cells. The results showed that the BL intensity with target bacterial cells was at least 100 times higher than that in the presence of interferent bacterial cells alone.

Specific capture of Salmonella onto immunomagnetic bead from a mixed culture containing an excess of $S$. aureus cells.

\begin{tabular}{|c|c|c|c|c|}
\hline Salmonella $(\mathrm{CFU} / \mathrm{mL})$ in suspension & S. aureus $(\mathrm{CFU} / \mathrm{mL})$ in suspension & S. aureus:Salmonella ratio & Salmonella $(\mathrm{CFU} / \mathrm{mL})$ on beads & S. aureus $(\mathrm{CFU} / \mathrm{mL})$ on beads \\
\hline $2.0 \times 10^{3}$ & $2.1 \times 10^{3}$ & $1.1: 1$ & $2.0 \times 10^{3}(98.5 \%)$ & $1.3 \times 10^{0}(0.06 \%)$ \\
\hline $1.7 \times 10^{3}$ & $1.9 \times 10^{4}$ & $10.7: 1$ & $1.4 \times 10^{3}(76.4 \%)$ & $2.1 \times 10^{1}(0.11 \%)$ \\
\hline
\end{tabular}



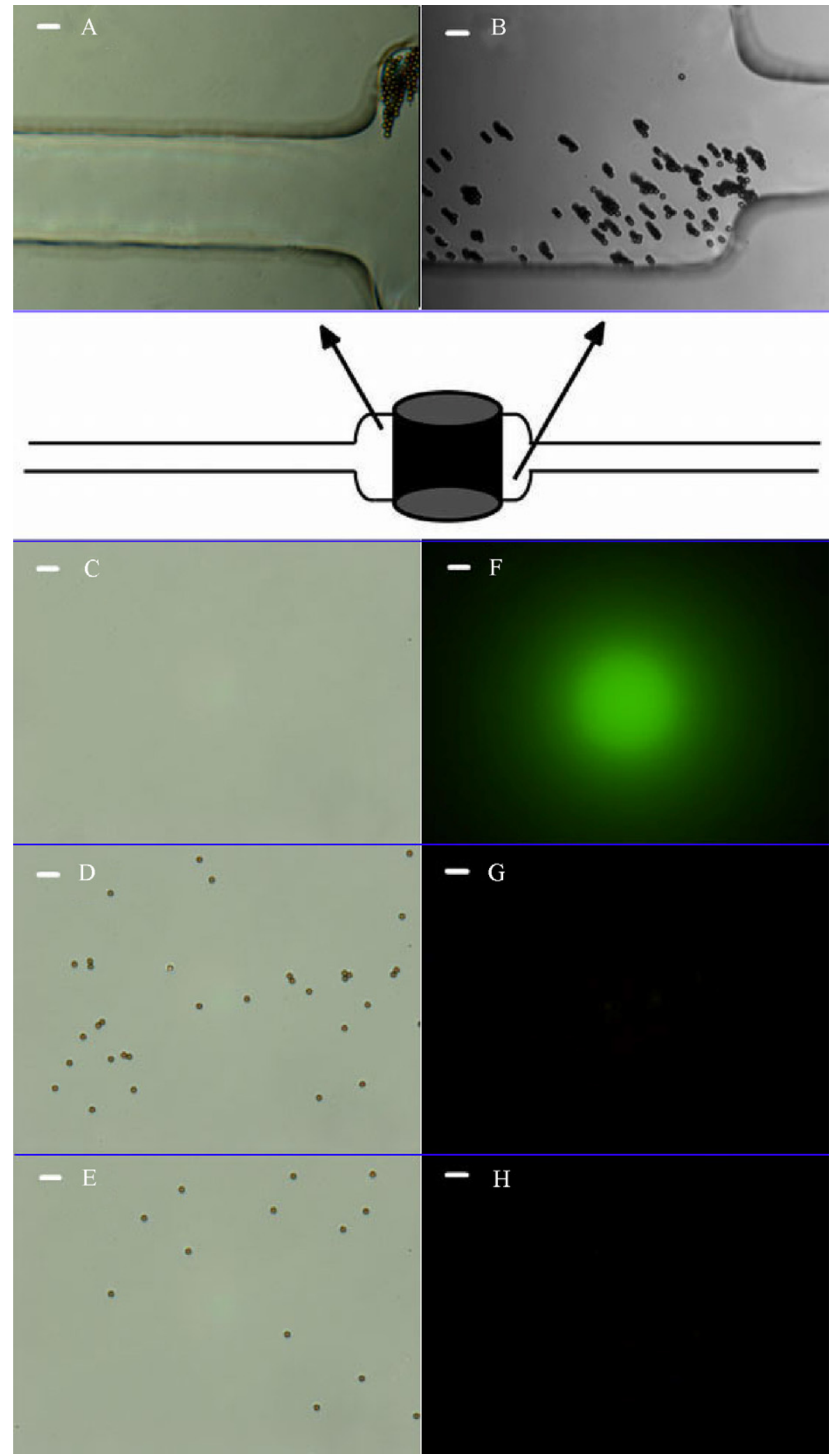

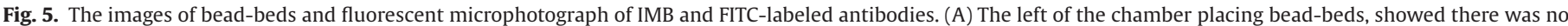

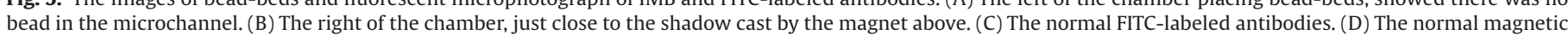

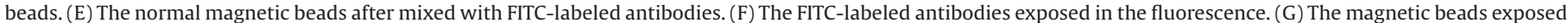
in the fluorescence. $(\mathrm{H})$ The magnetic beads after mixed with FITC-labeled antibodies exposed in the fluorescence. Scale bar $=10 \mu \mathrm{m}$. 


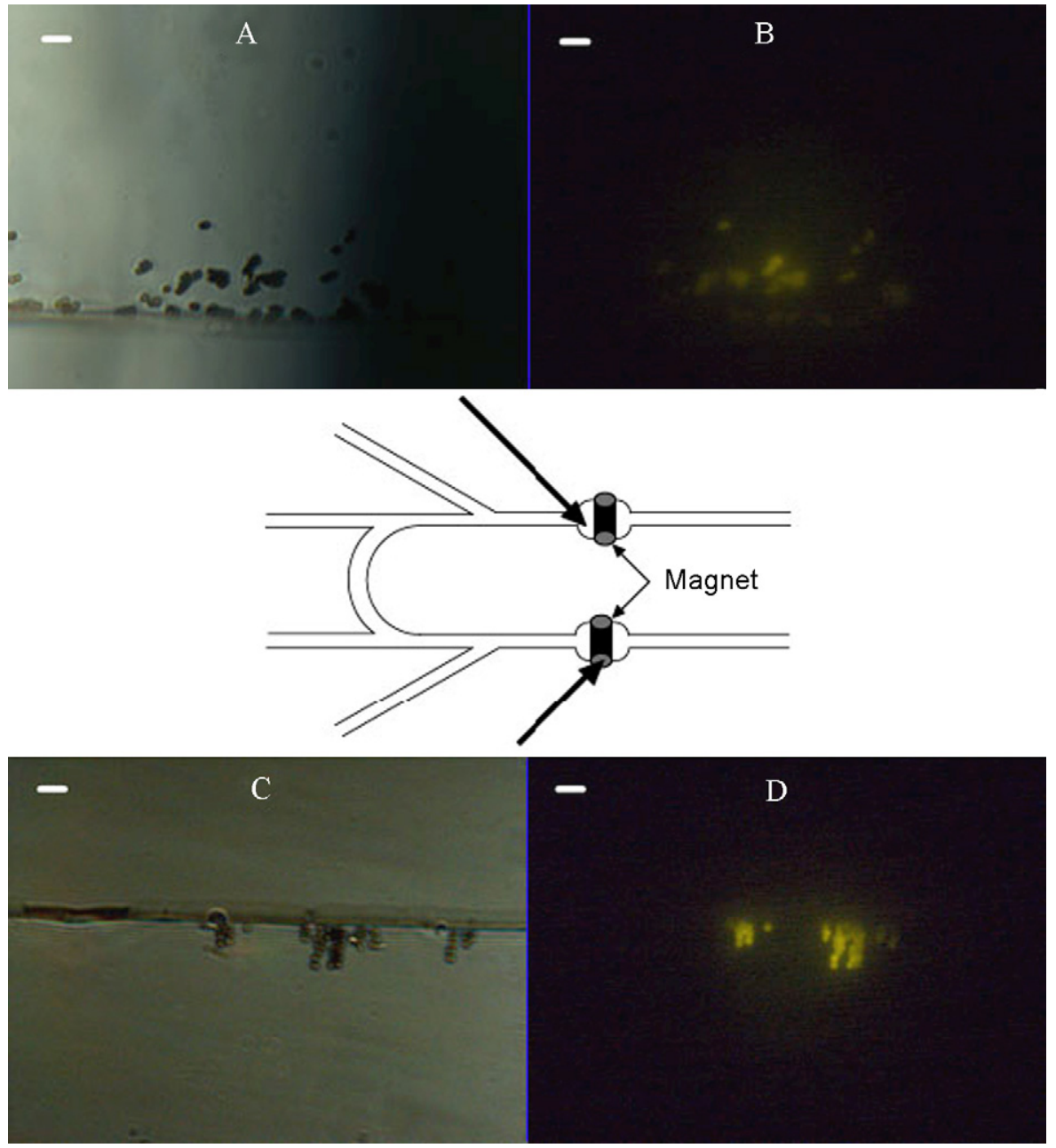

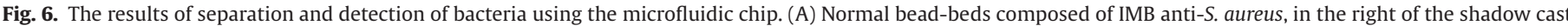

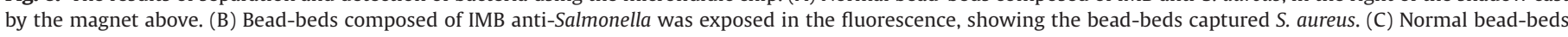

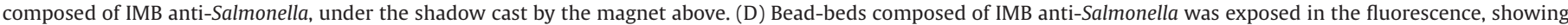
the bead-beds captured Salmonella. Scale bar $=10 \mu \mathrm{m}$.

\section{Conclusions}

We found that except for the inhibitory effect on luciferase, BAC can not only release ATP from bacterial cells, but also enhance the BL intensity at some range of concentration. In addition, high efficiency in separating bacterial cells can be achieved by employing immunomagnetic bead. As a result, a highly sensitive and rapid immune bioluminescence method was established for separating and detecting bacteria, which was applied to Salmonella in the presence of S. aureus as interferent. Furthermore, a U-type PDMS/glass microchip was developed to separate and detect bacteria simultaneously.

\section{Acknowledgements}

This work was supported by National Natural Science Foundation of China (No. 90813015), National Key Technology R\&D Program (2006BAK02A13) and National Basic Research Program of China (973 Program, No. 2007CB714507).

\section{References}

[1] M. Magliulo, P. Simoni, M. Guardigli, E. Michelini, M. Luciani, R. Lelli, A. Roda, J. Agric. Food Chem. 55 (2007) 4933.
[2] M. Zourob, S. Mohr, B.J.T. Brown, P.R. Fielden, M.B. McDonnellc, N.J. Goddard, Lab Chip 5 (2005) 1360.

[3] D.J. Squirrell, R.L. Price, M.J. Murphy, Anal. Chim. Acta 457 (2002) 109

[4] Y. Mine, J. Agric. Food Chem. 45 (1997) 3723.

[5] X.-L. Su, Y. Li, Anal. Chem. 76 (7) (2004) 1824

[6] F.C. Han, J. Luo, H.F. Zhang, D.C. He, X.J. Yan, World J. Microbiol. Biotechnol. 23 (2007) 1041

[7] H. Xu, G.-L. Zhang, F.-B. Zhang, Chem. Ind. Eng. (China) 20 (2003) 27.

[8] N. Hattor, T. Sakakibara, N. Kajiyama, T. Igarashi, M. Maeda, S. Murakami, Anal. Biochem. 319 (2003) 287.

[9] T. Kiesslich, C.B. Oberdanner, B. Krammer, K. Plaetzer, J. Biochem. Biophys. Methods 57 (2003) 247.

[10] E.N. Efremenko, R.E. Azizov, A.A. Raeva, V.M. Abbasov, S.D. Varfolomeyev, Int Biodeter. Biodegr. 56 (2005) 94.

[11] K. Fromell, G. Hulting, A. Ilichev, A. Larsson, K.D. Caldwell, Anal. Chem. 79 (2007) 8601.

[12] B.R. Branchini, T.L. Southworth, M.H. Murtiashaw, R.A. Magyar, S.A. Gonzalez M.C. Ruggiero, J.G. Stroh, Biochemistry 43 (2004) 7255

[13] N. Nakata, A. Oshoda, H. Tani, T. Kamidate, Anal. Sci. 19 (2003) 1183

[14] R.H. Liu, J. Yang, R. Lenigk, J. Bonanno, P. Grodzinski, Anal. Chem. 76 (2004) 1824

[15] T. Chen, J.-D. Lei, A.-J. Tong, Luminescence 20 (2005) 256.

[16] T. Taguchi, A. Arakaki, H. Takeyama, S. Haraguchi, M. Yoshino, M. Kaneko, Y Ishimori, T. Matsunaga1, Biotechnol. Bioeng. 96 (2007) 272

[17] B. Liu, M. Ozaki, H. Hisamoto, Q. Luo, Y. Utsumi, T. Hattori, S. Terabe, Anal. Chem 77 (2005) 573.

[18] A. Sin, S.K. Murthy, A. Revzin, R.G. Tompkins, M. Toner, Biotechnol. Bioeng. 91 (2005) 816.

[19] D.C. Duffy, J.C. McDonald, O.J.A. Schueller, G.M. Whitesides, Anal. Chem. 70 (1998) 4974.

[20] V.I. Furdui, D.J. Harrison, Lab Chip 4 (2004) 614

[21] M. Mujika, S. Arana, E. Castano, M. Tijero, R. Vilares, J.M. Ruano-López, A. Cruz, L. Sainz, J. Berganza, Biosens. Bioelectron. 24 (2009) 1253. 
[22] N. Bao, B. Jagadeesan, A.K. Bhunia, Y. Yao, C. Lua, J. Chromatogr. A 1181 (2008) 153.

[23] T. Kamidate, T. Kinkou, H. Watanabe, Anal. Biochem. 244 (1997) 62.

[24] T. Kamidate, K. Yanashita, H. Tani, A. Ishida, M. Notani, Anal. Chem. 78 (2006) 337.
[25] T. Kamidate, S. Niwa, N. Nakata, Anal. Chim. Acta 424 (2000) 169.

[26] B.R. Branchini, M.H. Murtiashaw, R.A. Magyar, N.C. Portier, M.C. Ruggiero, J.G. Stroh, J. Am. Chem. Soc. 124 (2002) 2112. 